\title{
Presigmoid Approach to Dumbbell Trigeminal Schwannoma
}

\author{
Katherine E. Kunigelis ${ }^{1} \quad$ Daniel Craig ${ }^{1} \quad$ Alexander Yang $^{1} \quad$ Samuel Gubbels $^{2} \quad$ A. Samy Youssef ${ }^{1}$
}

${ }^{1}$ Department of Neurosurgery, University of Colorado Hospital, Aurora, Colorado, United States

2 Department of Otolaryngology, University of Colorado Hospital, Aurora, Colorado, United States

\begin{abstract}
Address for correspondence A. Samy Youssef, MD, PhD, Department of Neurosurgery, University of Colorado Hospital, 12631 East 17th Avenue, Box C307, Aurora, CO 80045, United States (e-mail: samy.youssef@ucdenver.edu).
\end{abstract}

J Neurol Surg B 2018;79(suppl S5):S391-S392.

\begin{abstract}
Keywords

- trigeminal schwannoma

- dumbbell

- presigmoid

- cerebellopontine angle

This case is a 15-year-old male, presenting with headaches, right face, and arm numbness, and ataxia. MRI (magnetic resonance imaging) revealed a large right sided dumbbell shaped lesion, extending into the middle and posterior fossa with compression of the brainstem consistent with a trigeminal schwannoma. Treatment options here would be a retrosigmoid suprameatal approach or a lateral presigmoid approach. Given the tumor extension into multiple compartments, a presigmoid craniotomy, combining a middle fossa approach with anterior petrosectomy, and retrolabyrinthine approach with posterior petrosectomy were used to maximize the direct access corridor for resection. The petrous apex was already expanded and remodeled by the tumor. Nerve fascicles preservation technique is paramount to the functional preservation of the trigeminal nerve. The extent of resection should be weighed against the anatomical functional integrity of the nerve. Near total resection is considered if that means more nerve preservation. Postoperatively, the patient had a slight (House-Brackman grade II) facial droop, which resolved over days and developed right trigeminal hypesthesia at several weeks. This case is presented to demonstrate a combined petrosectomy technique for resection of lesions extending into both the middle and posterior cranial fossa with near total resection and trigeminal nerve preservation.

The link to the video can be found at: https://youtu.be/kA9GyFhL1dg.
\end{abstract}

Conflict of Interest

None.

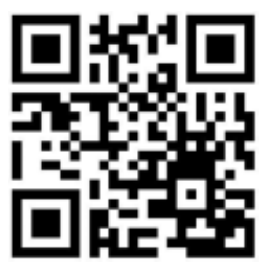

received

April 28, 2018

accepted

August 12, 2018

published online

September 25, 2018 www.thieme.com/skullbasevideos

www.thieme.com/jnlsbvideos

DOI https://doi.org/

10.1055/s-0038-1669977.

ISSN 2193-6331.
๑) 2018 Georg Thieme Verlag KG
Stuttgart · New York

License terms

(c) (1) $\ominus$ (\$) 


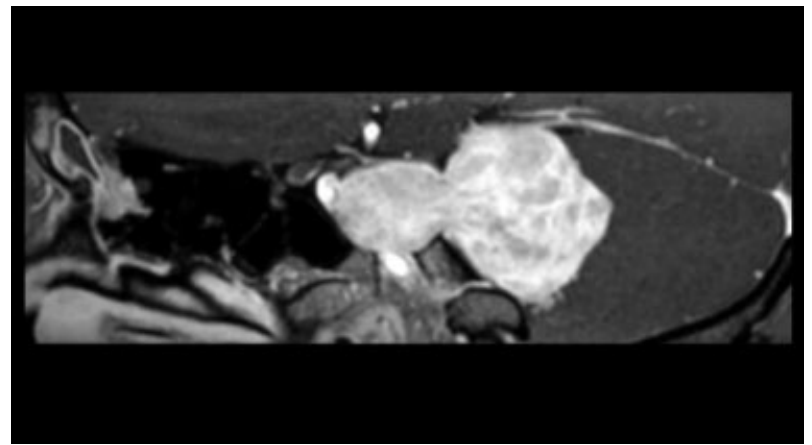

Fig. 1 Sagittal postcontrast MRI, showing dumbbell shaped trigeminal schwannoma in middle and posterior fossas.

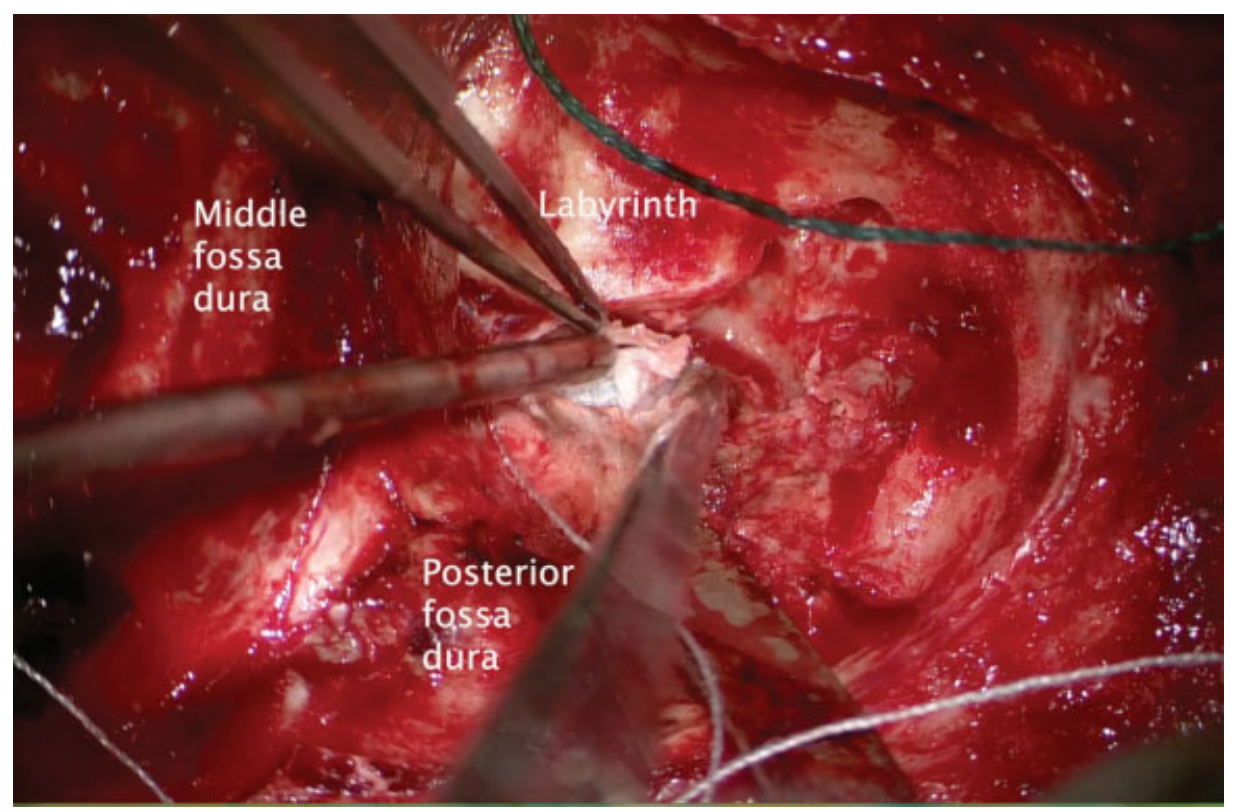

Fig. 2 Representative intraoperative anatomy of presigmoid approach. 